\title{
REVISITANDO O PEGMATITO ALTO SERRA BRANCA, MUNICÍPIO DE PEDRA LAVRADA (PB): MAPEAMENTO GEOLÓGICO, ASPECTOS DE CAMPO E ZONEAMENTO MINERAL
}

\author{
E. D. G. SALES*, L. C. M. L. SANTOS e F. F. VIEIRA \\ Unidade Acadêmica de Mineração e Geologia, Universidade Federal de Campina Grande \\ diegosales45@gmail.com*
}

Artigo submetido em novembro/2015 e aceito em dezembro/2015

DOI: $10.15628 /$ holos.2015.3750

\section{RESUMO}

Nas adjacências do município de Pedra Lavrada, (Paraíba), ocorrem uma série de corpos pegmatíticos, os quais compõe a Província Pegmatítica da Borborema. Compondo um grupo de pegmatitos economicamente importantes pela abundante ocorrência de minerais na região, destaca-se entre esses o Pegmatito Alto Serra Branca. Este pegmatito ocorre encaixado em xistos da Formação Seridó, sendo influenciado por zonas de cisalhamento locais dúcteis relacionadas ao Lineamento Patos e por fraturas de atitudes variáveis. Mapeamento geológico de detalhe, revelou que este corpo ocorre de maneira zonada, sendo definidas as zonas: i) contato, ii) intermediária externa, iii) intermediária interna e núcleo de quartzo. Estas zonas definem ocorrências preferenciais de minerais de valor econômico, como turmalinas e apatitas na nas zonas próximas a borda e cassiterita nas porções mais internas. Os dados obtidos nesta pesquisa sugerem que esta rocha corresponde a um pegmatito heterogêneo alojado ao longo de tenshion gashes em um evento regional de injeção de corpos pegmatíticos na Província Borborema.

PALAVRAS-CHAVE: Pegmatito heterogêneo, Alto Serra Branca, Pedra Lavrada, Nordeste do Brasil.

\section{REVISITING THE ALTO SERRA BRANCA PEGMATITE, PEDRA LAVRADA (PB) TOWN: GEOLOGICAL MAPPING, FIELD ASPECTS AND MINERAL ZONING}

\begin{abstract}
Nearby the Pedra Lavrada town, Paraíba, there are several pegmatitic bodies that are part of the Borborema Pegmatitic Province. Relative this important group of pegmatites, stands out the Alto Serra Branca Pegmatite. This body is hosted by schists of the Seridó Formation, being influenced by local ductile shear zones which are strongly related with the Patos Lineament, besides being affected by fractures of variable attitudes. Detailed geological mapping revealed that this rock has a typical
\end{abstract}

mineral zoning, which are: i) contact zone, ii) external intermediate zone, iii) internal intermediate zone and iv) quartz core. These zones define preferable mineral occurrences, such as tourmalines and apatites in the rim zones and cassiterite crystals in the inner zones. The obtained data suggests that such association corresponds to a heterogeneous pegmatite, that were emplacement along tension gashes in a regional event of pegmatite injection in the Borborema Province.

KEYWORDS: Heterogeneous pegmatite, Alto Serra Branca, Pedra Lavrada, Northeast Brazil. 


\section{INTRODUÇÃO}

Na região do Seridó nordestino, a qual abrange parte dos estados da Paraíba e Rio Grande do Norte, ocorrem uma série de corpos pegmatíticos, que representam reservas estratégicas de minerais industriais e gemas para o Brasil. Nas proximidades do município de Pedra Lavrada, Paraíba, destacam-se os pegmatitos Alto do Feio, Capoeira, Boqueirão e Alto Serra Branca (PASB), sendo este último objeto do presente estudo.

Esta região tem seu potencial econômico conhecido desde a década de 1930, com foco em diversos bens minerais como feldspatos, quartzo, berilos, além de gemas como a turmalina elbaíta, os quais têm sido explorados principalmente por meio de atividade garimpeira (Vasconcelos, 2006).

Na última década, diversos trabalhos científicos e tecnológicos têm sido desenvolvidos na região por meio de cooperação de diversas instituições públicas e privadas com objetivo de desenvolver a atividade mineral na região.

Adicionalmente, trabalhos científicos recentes, com destaque para Barreto et al., 2011, 2014; Soares et al., 2012, 2014; Bermanec et al., 2012 e Miranda, 2012 tem contribuído significativamente para o conhecimento petrológico, mineralógico e gemológico da Província Pegmatítica da Borborema (PPB), entretanto a região que compreende as adjacências de Pedra Lavrada, carece fortemente de trabalhos de geologia básica, envolvendo mapeamento de corpos pegmatíticos em escala de detalhe e definição de zonas de ocorrências minerais ao longo desses corpos.

O principal objetivo deste trabalho é apresentar novos dados de cartografia e geologia básica do Pegmatito Alto Serra Branca (PASB), visando contribuir para a o conhecimento geológico da área e futuros trabalhos prospectivos na região. Adicionalmente, este trabalho visa contribuir para o desenvolvimento e aprimoramento da extração dos minerais de valor econômico pela cooperativa garimpeira que atua neste depósito mineral.

\section{FUNDAMENTAÇÃO TEÓRICA}

O termo pegmatito foi pioneiramente utilizado em 1800 pelo mineralogista Hafly, tendo definido esta rocha em função do repetitivo intercrescimento geométrico entre quartzo e feldspato alcalino, notadamente microclina, hoje denominado de intercrescimento gráfico. Do ponto de vista prático, pegmatitos são rochas magmáticas félsicas e caracterizadas por uma textura extremamente grossa. Adicionalmente, pegmatitos são rochas muito importantes do ponto de vista econômico, pois podem ser portadoras de elementos estratégicos para a indústria, tais como $\mathrm{Ta}, \mathrm{Nb}, \mathrm{Be}, \mathrm{Sb}, \mathrm{W}$, elementos terras-raras, além de concentram grande parte das gemas utilizadas em joalherias.

Uma definição completa para essas rochas foi proposta por London (2008), o qual define pegmatitos como "rochas ígneas de composição granítica, as quais se distinguem de outras rochas magmáticas por sua granulação extremamente grossa ou por abundância de cristais exibindo textura gráfica ou com hábitos de intercrescimento fortemente direcionais, além de possuir zoneamentos minerais bem definidos".

Um aspecto particularmente importante do ponto de vista geológico em pegmatitos é o seu zoneamento interno, o qual concentra em certas porções dos corpos, fases minerais específicas. 0 zoneamento genérico proposto por Cameron et al., (1949), é atualmente o mais utilizado e leva em consideração variações mineralógicas e aspectos texturais específicos presentes 
principalmente em pegmatitos graníticos. Obviamente, existem vários exemplos de pegmatitos não zonados, os quais são normalmente associados com rochas encaixantes de alto grau metamórfico, formadas no campo de estabilidade da cianita e espodumênio (Horton et al., 1987).

De uma maneira simplificada, o esquema proposto por Cameron et al., (1949) define as seguintes zonas em pegmatitos graníticos: i) zonas de borda, ii) zonas de parede, iii) zonas intermediárias e iv) núcleo. A zona de borda envolve a porção mais externa do corpo pegmatítico e o resultado de sua interação com as rochas encaixantes, enquanto que as zonas de parede (de difícil identificação) são regiões externas mais espessas que zonas de bordas e caracterizadas por orientação anisotrópica de sua mineralogia, podendo conter cristais de tamanhos variados de turmalina, berilo, mica e feldspatos.

Por outro lado, as zonas intermediárias são normalmente marcadas por um aumento considerável no tamanho dos cristais e intensa variabilidade mineralógica. É nesta zona que normalmente ocorrem minerais "nobres", tais como gemas e minerais metálicos. Por último, o núcleo de pegmatitos zonados é sempre a região mais homogênea, sendo composto por fases silicáticas residuais tais como quartzo ou albita, com eventual ocorrência de muscovita e lepidolita, além de minerais raros que ocorrem de forma disseminada.

\section{ASPECTOS GEOLÓGICOS REGIONAIS}

O PASB faz parte da Província Pegmatítica da Borborema (Figura 1), a qual se encontra inserida Domínio Rio Grande do Norte da Província Borborema.

A Província Borborema foi definida por Almeida et al., (1981), como uma entidade geotectônica brasiliana, que ocupa a porção nordeste da plataforma sul-americana. 0 estado de conhecimento atual da Província Borborema é definido por sua subdivisão em cinco subprovíncias ou domínios geotectônicos distribuídos de norte para sul como: Médio Coreaú, Ceará Central, Rio Grande do Norte, Transversal e Meridional (Brito Neves et al., 2000; Santos et al., 2000).

Distribuídos ao longo dessas subprovíncias ocorrem núcleos arqueanos, ampla exposição de ortognaisses e migmatitos de idade paleoproterozoica (na subprovíncia Setentrional), cinturões de rochas supracrustais estaterianas, meso a neoproterozoicas, além de diversas associações de rochas associadas a arcos magmáticos neoproterozoicos, incluindo intenso plutonismo brasiliano (Santos et al., 2000; Brito Neves et al., 2000).

A estruturação geral deste conjunto é controlada por complexas redes de zonas de cisalhamento e lineamentos que possuem continuação para as faixas pan-africanas. Adicionalmente, algumas dessas estruturas são interpretadas como importantes zonas de suturas materializadas por extensos corredores miloníticos, com destaques para os lineamentos Transbrasiliano, Patos e Pernambuco (Brito Neves et al., 2000).

Por outro lado, o Domínio Rio Grande do Norte corresponde a região localizada entre o lineamento Patos e a zona de cisalhamento Senador Pompeu (Brito Neves et al., 2000; Santos et al., 2000). Dentro deste domínio, os pegmatitos mineralizados ocorrem de forma intrusiva em biotita-xistos, granada-biotita xistos e xistos ricos em biotita alterados da Formação Seridó da Faixa homônima. De acordo com Van Schmus et al., (2003), essas rochas foram recristalizadas com um metamorfismo do tipo LP/HT (baixa pressão e alta temperatura), tendo idade de deposição Neoproterozoica, constituindo uma zona mineralizada em $\mathrm{W}$ e outros metais raros. O PASB faz parte de uma das inúmeras intrusões magmáticas que compões a Província Pegmatítica da Borborema. Esta província foi pioneiramente definida por Scorza, 1944, tendo seu potencial econômico conhecido desde a primeira guerra mundial, ocupando uma área de $75 \times 150 \mathrm{~km}$ na 
porção centro-sul da Faixa Seridó, sendo intensamente afetada por diversas estruturas dúcteis na direção NE (Araújo et al., 2005, Beurlen et al., 2014)

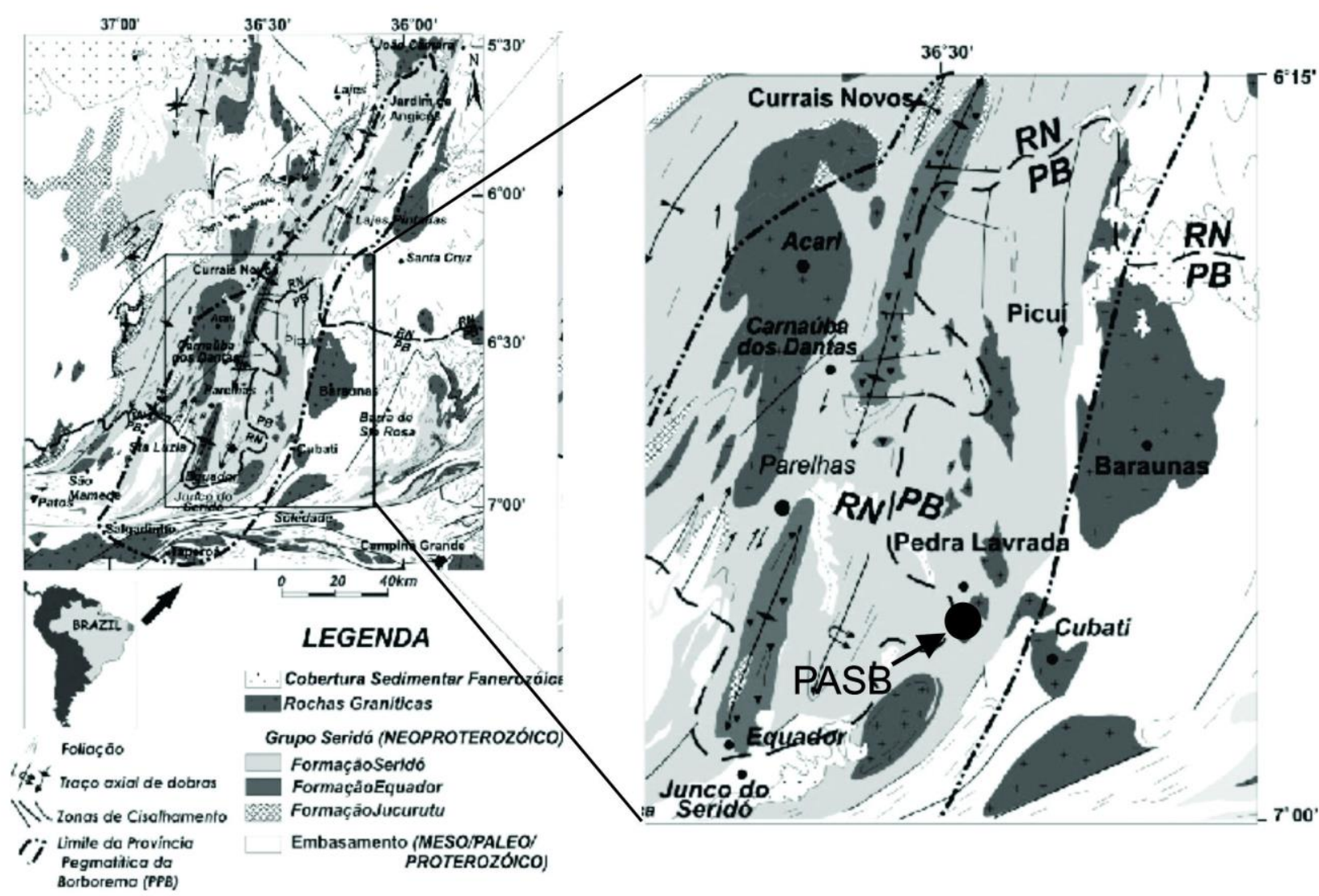

Figura 1: Contexto geológico da Província Pegmatítica da Borborema. Modificado de Beurlen et al., (2009) e Soares et al., (2011).

\section{METODOLOGIA}

Para o desenvolvimento do presente trabalho foi seguida sistemática básica de mapeamento geológico de detalhe e pesquisa mineral qualitativa de superfície. A metodologia empregada envolveu:

- Interpretação das principais estruturas em fotografias aéreas e imagens de satélite;

- Etapas de campo onde foram coletados dados geodésicos e estruturais por meio de auxílio de equipamento GPS e bússola;

- Coleta de amostras para análises petrográficas no laboratório de microscopia da Unidade Acadêmica de Mineração e Geologia da Universidade Federal de Campina Grande;

- Trabalhos de gabinete onde os dados estruturais foram tratados e foi confeccionado o mapa geológico de detalhe com a integração de todos os dados por meio de software Arcgis, versão 9.3.

\section{RESULTADOS}

Durante o presente trabalho, foram realizados perfis transversais à direção do PASB com o objetivo de identificar as principais feições geológicas e zonas mineralizadas deste corpo.

Durante o presente trabalho, foi observado que este corpo pegmatítico possui uma forma elíptica, orientada na direção NE-SW, em função da atividade de zonas de cisalhamento sinistrais 
relacionadas ao Lineamento Patos, apresentando destaque topográfico com relação às rochas encaixantes em função de sua maior resistência ao intemperismo na região. Estas estruturas regionais conferem as rochas encaixantes e as regiões de borda do PASB estruturas de caráter dúctil, tais como foliação de médio a alto ângulo, associado a lineações horizontais à subhorizontais e dobramentos em escala métrica a dessimétrica com planos axiais subverticais, observados freqüentemente nos xistos encaixantes. Por outro lado, este pegmatito é cortado por fraturas locais, algumas mapeáveis e outras observáveis apenas em escala de afloramento, sugerindo que uma fase deformacional rúptil desempenhou papel importante na formação deste pegmatito.

Análise mesoscópica indicou que o PASB se apresenta com presença de cristais com granulação grossa da ordem de dezenas de centímetros e textura fanerítica a pegmatítica. Possuindo presença significativa de minerais félsicos, sendo portanto classificada como uma rocha predominantemente leucocrática.

Observações de campo e coleta sistemática de amostras permitiu definir as seguintes zonas minerais que ocorrem da borda para o centro do corpo pegmatitíco: i) zona de contato, ii) zona intermediária externa, iii) zona intermediária interna e iv) núcleo de quartzo, conforme mapa geológico apresentado na Figura 2. A distribuição das zonas mapeadas e das principais estruturas observadas, as quais incluem a foliação regional foto-interpretada (observada nos xistos encaixantes) e fraturas que cortam o corpo, podem ser obervadas no perfil geológico esquemático apresentado na Figura 3.

Adicionalmente, estudos estruturais de detalhe em perfis paralelos e perpendiculares ao trend do PASB permitiu mapear e identificar as principais fraturas que cortam o corpo. Uma análise geométrica destas estruturas revelou que o corpo pegmatítico é cortado por três principais famílias de fraturas, cujas direções são preferencialmente: N-S, NW-SE e NE-SW (Figura 4).

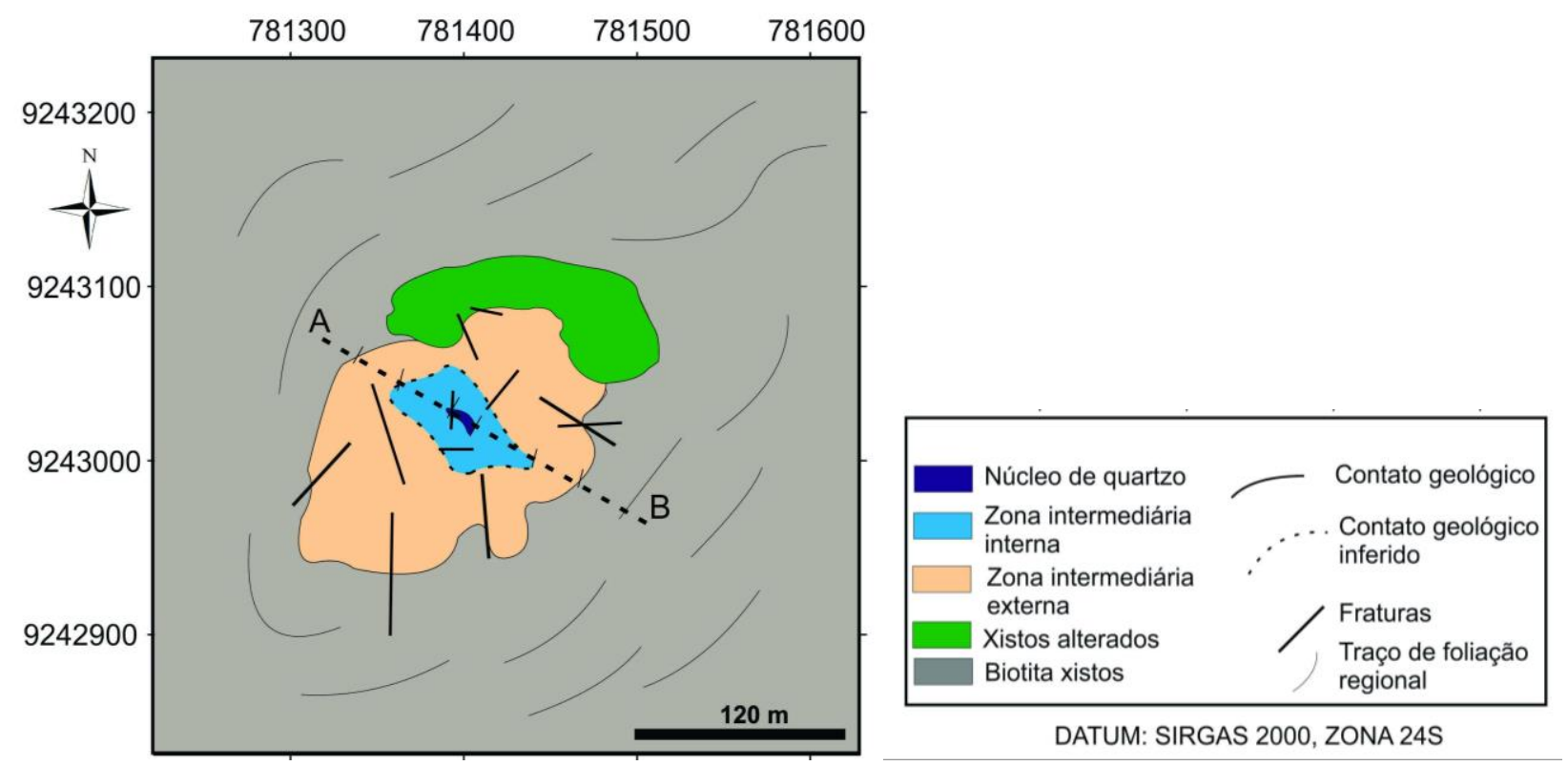

Figura 2: Mapa geológico e zoneamento mineral proposto para o pegmatito Alto Serra Branca. 


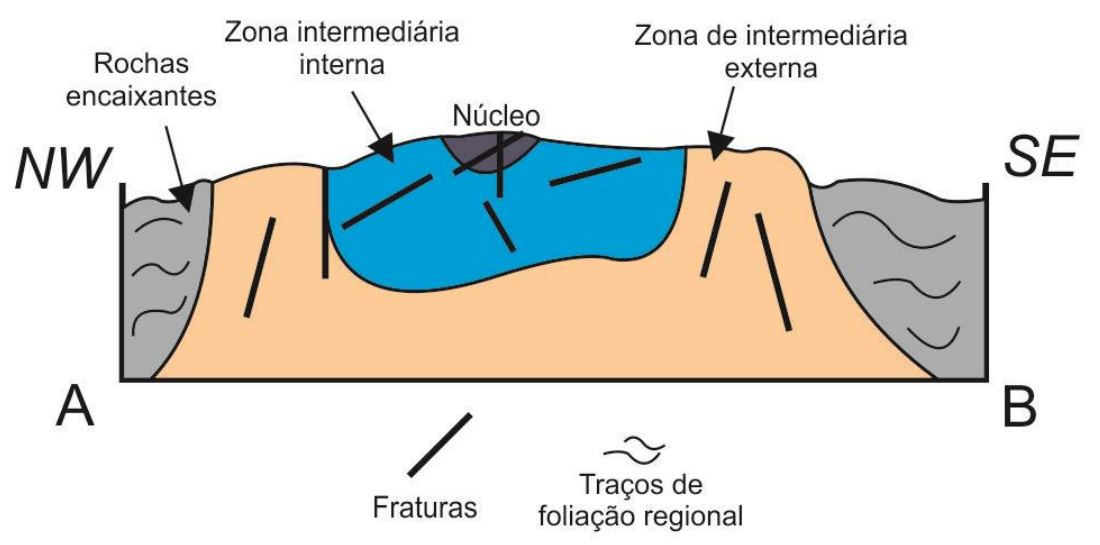

Figura 3: Perfil geológico esquemático A-B representado na figura 2, mostrando a distribuição espacial das principais zonas minerais e estruturas do PASB (Fora de escala).

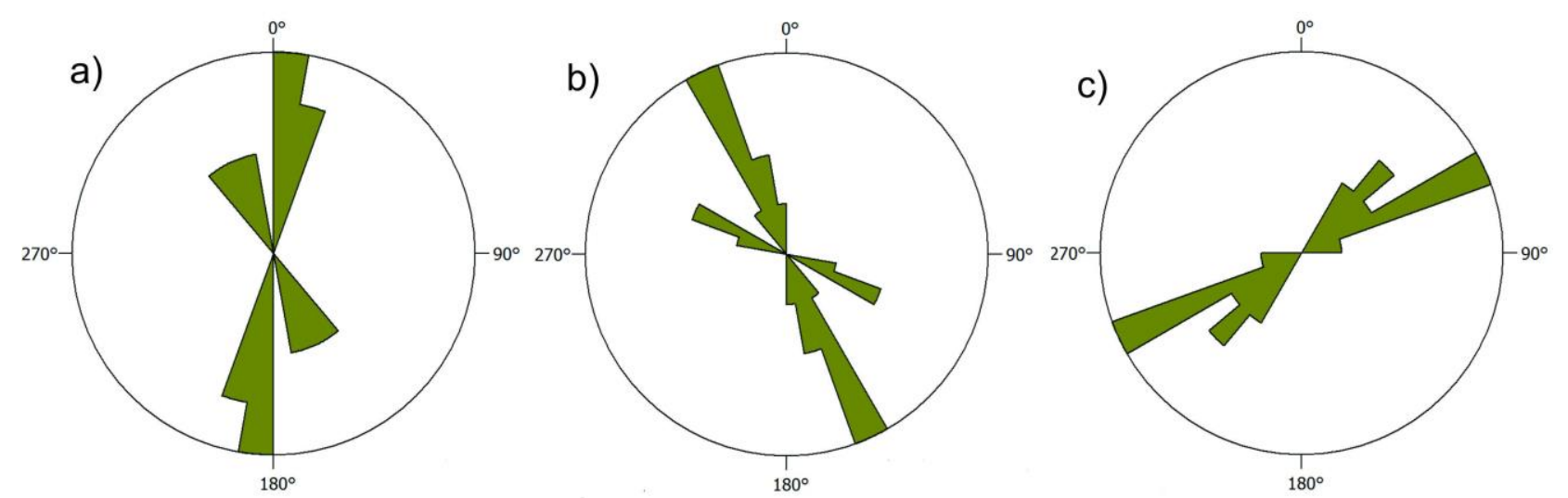

Figura 4: Diagramas de roseta demonstrando o comportamento das principais famílias de fraturas medidas durante as etapas de campo.

A região que compõe as porções de borda do corpo pegmatítico e os xistos encaixantes é aqui definida como zona de contato, a qual é representada por um forte contraste topográfico entre o PASB e os xistos ao redor (Figura 5a). Esta zona é caracterizada pela ocorrência de estruturas dúcteis referentes à foliação regional as quais são cortadas por veios e diques pegmatíticos enriquecidos em quartzo e feldspato potássico. Pequenos filetes aplíticos ocorrem cortando a foliação sendo interpretados como o resultado da injeção fluídos tardios do PASB nas rochas encaixantes.

A zona intermediária externa é caracterizada pela presença de feldspato potássico abundante, por vezes enriquecido com mineralizações de turmalina preta (variedade schorllita), mica muscovita em placas ou exibindo ábito radial, ambligonita (fosfato de lítio) e albita. Apatita ocorre localmente exibindo cristais subédricos disseminados, sempre relacionados aos cristais de albita. Adicionalmente, os cristais de albita apresentam-se ocasionalmente com oxidação de intensidade variável, o que reduz a dureza deste mineral passando a ter consistência friável em tonalidades que variam do vermelho ao branco. Granada de coloração marrom-escura pode ocorrer subordinadamente, exibindo freqüentemente sua forma dodecaédrica, constituindo cristais perfeitamente euédricos, tendo ocorrência mineral de forma disseminada.

A abundância de turmalina aparentemente apresenta uma estreita relação com a presença de feldspato potássico, sugerindo que o enriquecimento do primeiro depende da presença do segundo, revelando assim um possível guia prospectivo. Essa relação embora que empírica, é 
observada ao longo de todos os perfis, inferindo portanto um controle mineralógico para a ocorrência da turmalina. Por outro lado, a ausência de feldspato potássico tende a favorecer o desenvolvimento de cristais de albita, os quais são sempre acompanhados da associação muscovita \pm apatita.

A zona intermediária interna por sua vez possui mineralogia simples, sendo formada pela associação feldspato + quartzo associada a diminuição da granulometria da rocha, assumindo preferencialmente uma textura fanerítica, típica de rochas graníticas. A feição geológica marcante desta zona é a presença de textura gráfica (Figura 5b), relacionada ao intercrescimento "vermiforme" destes minerais silicáticos. Esta textura é freqüentemente associada ao crescimento em desequilíbrio de quartzo e feldspato nos últimos estágios da cristalização magmática.

Além disso, nesta zona ocorrem ainda porções dominadas exclusivamente por albita. Nestas regiões, minerais com valor econômico importante como ambligonita e afrisita, além de diminutas ocorrências de elbaítas azuis safira estão presentes de forma disseminada.
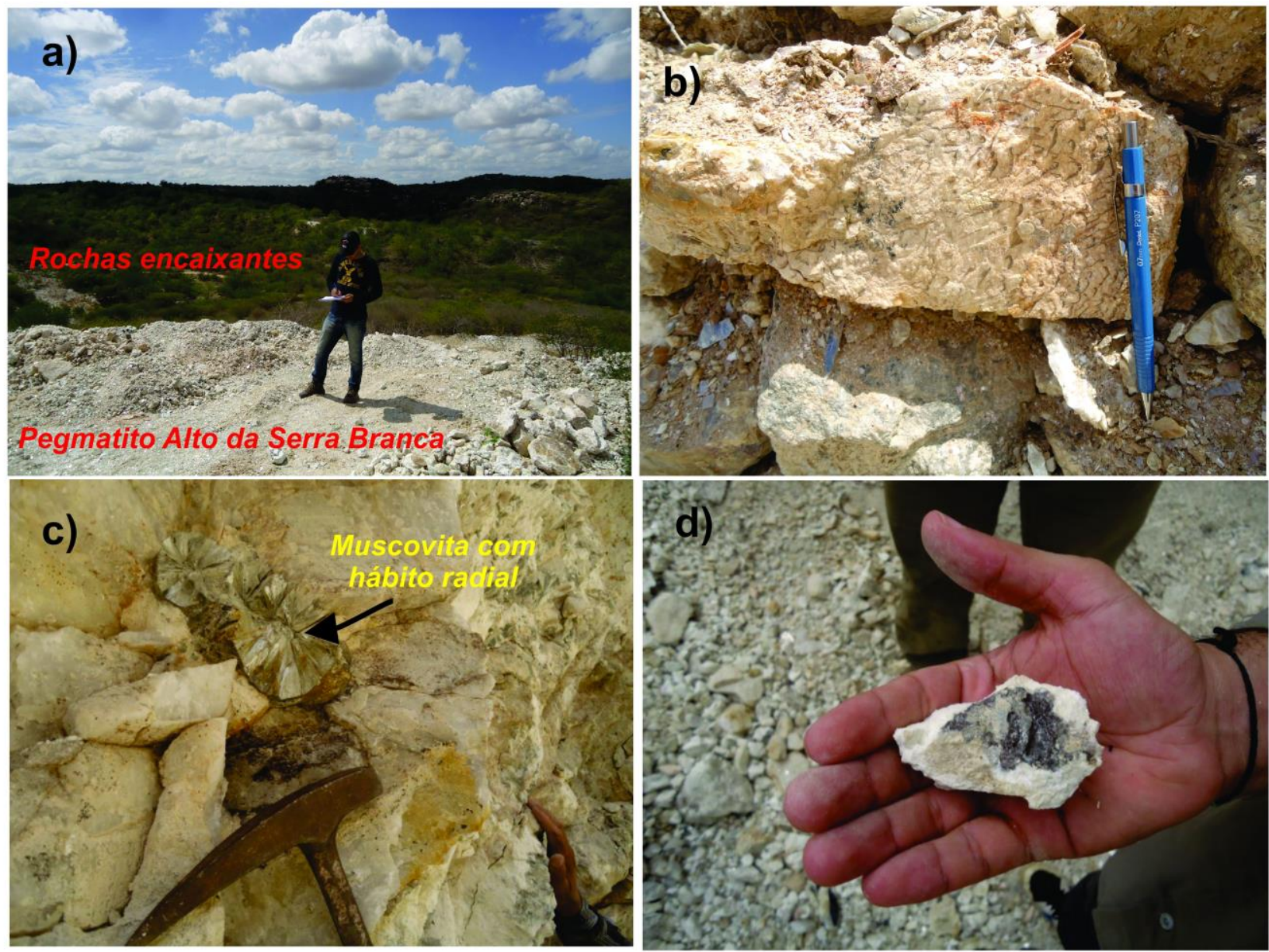

Figura 5: Aspectos de campo observados ao longo dos perfis realizados neste estudo. a) Discordância topográfica entre o Pegmatito Alto Serra Branca e as rochas encaixantes, b) Aspecto mesoscópico de afloramento referente a zona intermediaria externa predominância de feldspato potássico e presença subordinada de schorlita e granada, c) Detalhe de muscovita com raro hábito radial observada na região de núcleo de quartzo (porção central do PASB) e d) Crital de cassiterita coletado ao longo de perfil na região do nucleo de quartzo.

Por último, mas não menos importante, na região central deste pegmatito ocorre uma região fortemente homogênea, tendo sua mineralogia limitada por cristais anédricos, de dimensões variadas de quartzo com coloração variada. Esta região é aqui denominada de núcleo de quartzo, sendo caracterizada por intenso fraturamento, e apesar de ocorrer localmente às variações 
azuladas, amareladas (citrino), esfumaçadas (fumê) e transparentes (hialino) em função da presença de impurezas, a predominância principal é de quartzo na sua variação esbranquiçada mais comum (quartzo leitoso).

Estimativas realizadas sugerem que este núcleo corresponde a um bolsão de sílica de dimensões inferiores a outros pegmatitos da região, com extensão aproximada de 12 metros ao longo do seu eixo principal.

Minerais subordinados que ocorrem nessa zona sendo observada a presença de micas de variedade muscovita, podendo exibir hábito radial concêntrico (Figura 5c), ou mesmo lamelar característico, além de cristais disseminados de cassiterita como principal mineral metálico presente nesta zona (Figura $5 \mathrm{~d}$ ). Estes minerais constituem os principais minerais acessórios desta porção do pegmatito.

\section{DISCUSSÃO}

Mapeamento geológico de corpos pegmatíticos na região do Seridó representam contribuição importante para o melhor conhecimento das ocorrências minerais dessa região. No presente trabalho, apresentamos dados de campo e mapeamento geológico de detalhe do pegmatito Alto Serra Branca, o qual ocorre nas adjacências do município de Pedra Lavrada (PB).

Os dados obtidos confrontam e corroboram com resultados obtidos em trabalhos anteriores realizados neste pegmatito (eg. Soares, et al., 2011). Entretanto, estes autores definem uma zona como zona de parede, a qual não foi observadas em nossos perfis, sugerindo que está zona pode fazer parte de uma das zonas definidas no presente trabalho ou as mineralizações contidas nessa zona foram totalmente exauridas devido a atividade de mineração local.

A definição de zonas realizadas no presente trabalho permite a concepção de um guia de exploração mineral qualitativa, onde as zonas intermediárias externas e interna e a zona de núcleo, concentram mineralogia específica característica de cada região do corpo pegmatítico.

A variação mineral observada no presente trabalho é similar a observada em outros corpos pegmatíticos na região, como por exemplo, o pegmatito Alto do Feio (Genuíno et al., 2015), sugerindo que essas rochas devem pertencer a um mesmo pulso ou pulsos de idade similar de cristalização tardia de corpos graníticos que são descritos nas proximidades (CPRM, 2005).

Adicionalmente a presença de zonas de contato, bordas e núcleo homogêneo de quartzo, permite classificar o PASB como um pegmatito tipicamente heterogêneo, de acordo com a classificação de Johnston (1945), além de corresponder de forma relativamente fiel aos modelos de zoneamento para pegmatitos graníticos empregados em diversas províncias pegmatíticas ao redor do mundo, conforme demonstram Cameron (1949) e London (2011).

Por outro lado, zoneamento similar é apresentado por Soares et al., (2011). Estes autores descrevem uma mineralogia similar para essas rochas com exceção de turmalina elbaíta azulada, a qual não foi observada durante a nossa pesquisa. Entretanto, algumas zonas descritas por estes autores não são facilmente observáveis como a zona de parede, o que provavelmente é reflexo da constante extração de minério no PASB. Adicionalmente, o presente trabalho esboça um mapa geológico onde as determinadas zonas são definidas espacialmente, incluindo as principais estruturas presentes.

Realizando análises estruturais regionais e estudos sobre o alojamento de corpos pegmatíticos na Província Pegmatítica da Borborema, Araújo et al., (2000), definiu dois principais estágios de geração de pegmatitos: i) um evento mais antigo relacionado ao alojamento de pegmatitos homogêneos ao longo de descontinuidades estruturais e ii) pegmatitos heterogêneos alojados ao longo de veios de tensão (tension gashes) e estruturas dilatacionais relacionadas a 
faces de deformação tardias das zonas de cisalhamento. Neste sentido, sugerimos que o PASB foi alojado ao longo de superfícies rúpteis, correspondentes ao segundo evento definido por Araújo et al., (2000).

\section{CONCLUSÕES}

Os resultados obtidos no presente trabalho podem ser sumarizados a seguir:

I) O pegmatito Alto Serra Branca possui um trend regional NE-SW e ocorre encaixado em xistos da Formação Seridó da Faixa de Dobramento Seridó;

II) Este corpo é influenciado por foliação de alto ângulo dúctil e também cortado por fraturas e outras estruturas rúpteis. Durante trabalhos de mapeamento geológico, foram identificados três principais famílias de fraturas, cujas direções preferenciais são: N-S, NW-SE e NE-SW.

III) Mapeamento geológico de detalhe revelou que este corpo possui um zoneamento mineral característico, marcado pela ocorrência de minerais-minério em função destas zonas. Foram definidas as zonas de contato entre o pegmatito e rocha encaixante, zona intermediária externa, composta pela associação feldspato potássico + schorllita, muscovita + ambligonita + albita, zona intermediária interna, formada pela associação quartzo + feldspato potássico exibindo intercrescimento gráfico e núcleo homogêneo de quartzo, composto por associações pontuais de muscovita radial e cassiterita;

IV) O zoneamento mineral observado sugere que o PASB corresponde a um pegmatito heterogêneo injetado em uma zona de deformação rúptil (tension gashes), a qual é interpretada como o principal aspecto estrutural para o alojamento de pegmatitos dessa natureza na região.

\section{AGRADECIMENTOS}

O presente trabalho é resultado do trabalho final de curso (TFC) do primeiro autor sob a orientação do segundo autor. Os autores agradecem ao Centro de Tecnologia Mineral (CETEM) pelo financiamento da pesquisa por meio do projeto intitulado "Projeto de pesquisa e desenvolvimento tecnológico voltado para o aproveitamento regional e sustentável de minerais de pegmatitos e rochas de quartzitos e a cooperativa de garimpeiros de Pedra Lavrada que nos auxiliou durante todas as etapas da pesquisa. Agradecimentos adicionais são referidos ao editor chefe da Revista Holos, Professor José Yvan Leite por todo auxílio prestado durante a submissão deste manuscrito, bem como as sugestões dos revisores, as quais foram particularmente importantes.

\section{REFERÊNCIAS}

1. ALMEIDA, F. F. M. de; BRITO NEVES, B. B.; FUCK, R. A. Brazilian Structural provinces: An introduction. In: Earth Science Review, v.17, p.1-29, 1981.

2. ARAÚJO, M.N.C; SILVA, F.C.A; JARDIM DE SÁ, E.F. Pegmatite emplacement in the Seridó Belt, Northeastern Brazil: Late stage kinematics of the Brasiliano Orogen. In: Gondwana Research, v. 4, p. 75-85, 2011. 
3. BARRETO, S. B.; GUZZO, P. L.; SOUZA NETO, J. A.; MORAIS, P. A. R.; CARVALHO JR, A. B.; KHOURY, H. J. Spectroscopic Study of Rose Quartz from the Taboa Pegmatite (Borborema Province, Brazil) Irradiated with High Gamma Doses. Estudos Geológicos. Série B, Estudos e Pesquisas (UFPE), Recife, v. 19, p. 52-61, 2009.

4. BARRETO, S.B.; COBIC, A.; GOBAC, Z.Z.; BERMANEC, V.; KNIEWALD, G. Chemical characterization and chromophore elements in elbaites from Borborema Province, Brazil. In: Associación Geológica Argentina, Série D, Publicación Especial, v.14, p.41-44, 2011.

5. BERMANEC, V; HORVAT, M.; ZIGOVECKI, G. Z.; ZEBEC, V.; SCHOLZ, R.; SKODA, R.; WEGNER, R.; BRITO, B. S. D.; DODONY, I. Pseudomorphs of Low Microcline After Adularia Fourlings from the Alto Da Cabeca (Boqueirao) and Morro Redondo Pegmatites, Brazil. Canadian Mineralogist, v. 50, p. 975-987, 2012.

6. BRITO NEVES, B. B. de; SANTOS, E. J. dos; VAN SCHUMS, W. R. Tectonic history of the Borborema Province. In: CORDANI, U. G.; MILANI, E. J.; THOMAZ FILHO, A.; CAMPOS, D. A. (Eds.) Tectonic evolution of South America. Rio de Janeiro: 31st. International Geological Congress, 854 p., p.151-182. 2000.

7. CAMERON, E.N.; JANHS, R.H.; MCNAIR, A.H.; PAGE, L.R. Internal structure of granitic pegmatites. Economic Geology Monograph, v. 2, 115 pp, 1949.

8. GENUÍNO, V.A.; SANTOS, L.C.M.L.; VIEIRA, F.F. Considerações Sobre O Pegmatito Alto Do Feio: Aspectos Estruturais, Mineralógicos e Guia Prospectivo Preliminar. In: Simpósio de Geologia do Nordeste, 26., Natal. 2015.

9. HORTON, J.W.; SUTTER, J.F.; STERN, T.W.; MILTON, D.J. Alleghanian deformation, metamorphism and granite emplacement in the central Piedmont of the southern Appalachians. American Journal of Science, v. 287, p. 635-660. 1987.

10. JOHNSTON Jr., W. D. Pegmatitos ambligonita-berilo-tantalíferos do Ceará, Nordeste do Brasil. Rio de Janeiro: DNPM/ Divisão de Fomento da Produção Mineral. (avulso, 66). 1945.

11. LONDON, D. Pegmatites. Canadian Mineralogist Special Publication, v. 10, 347 pp. 2008.

12. MIRANDA, M. R. Caracterização espectroscópica e alteração da cor por radiação gama e tratamentos térmicos de quartzo róseo-leitoso da Província Pegmatítica da Borborema. (Dissertação) Programa de pós-graduação em Engenharia Mineral. UFPE, Recife, 2012.

13. SANTOS, E.J.; BRITO NEVES, B.B.; VAN SCHMUS, W.R.; OLIVEIRA, R.G.,; MEDEIROS, V.C. An overall view on the displaced terrane arrangement of the Borborema Province, NE Brazil. In: International Geological Congress, 31th, Rio de Janeiro, Brazil, General Symposia, Tectonic Evolution of South American Platform, p.5-9. 2000.

14. SOARES, D. R.; FERREIRA, A. C. M.; BEURLEN, H.; LIMA, R. J. S.; SUASSUNA FILHO, J.; LOURENÇO NETO, M. Estudo de espectroscopia de absorção uv-vis da gahnita gemológica do pegmatito alto mirador, província pegmatítica da borborema, NE do brasil. Estudos geológicos(UFPE), Recife, v. 22, p. 20-30, 2012.

15. SOARES, D. R; BEURLEN, H.; FERREIRA, A. C. M.; GONZAGA, F. A. S. Crisoberilo: primeira ocorrência na Província Pegmatitica da Borborema. Principia, João Pessoa, v. 22, p. 401-44, 2014.

16. SPARES, D.R.; FERREIRA, A.C.M.; BEURLEN, H.; FERREIRA, J.A.M.; YADAVA, R.; MAIOR, I.S. Elbaíta azul de qualidade gemológica do pegmatito Alto Serra Branca, Pedra Lavrada, Paraíba. 
Estudos Geológicos (UFPE). v. 21, p. 123-133. 2011.

17. VAN SCHMUS, W. R.; BRITO NEVES, B. B.; WILLIAMS, I. S.; HACKSPACHER, P. C.; FETTER, A. H.; DANTAS, E. L.; BABINSKI, M. The Serido Group of NE Brazil, a late Neoproterozoic pré- to syncollisional basin in West Gondwana: insights from Shrimp U-Pb detrital zircon ages and Sm-Nd crustal residence (TDM) ages. Precambrian Research, 127:287-327, 2003.

18. VASCONCELOS, S. A. O uso do território do município de Pedra Lavrada-PB pela mineração. 2006. 216 f. (Dissertação) Programa de pós-graduação, curso de mestrado e doutorado em geografia. UFPE, Recife. 2006. 